\title{
CREATION OF KNOWLEDGE - BASED ECONOMY IN THE EUROPEAN UNION: THE MAIN TYPICALITIES AND NEW IDEAS OF CLUSTERIZATION
}

\author{
Borisas Melnikas \\ Vilnius Gediminas Technical University, Sauletekio al. 11, LT-10223 Vilnius-40, Lithuania, \\ e-mail:melnikas@vv.vtu.lt
}

Received 1002 2005; accepted 07042005

\begin{abstract}
Possibilities for the development of new forms of economic, social and technological headway designed to create and further improve economies based on knowledge are analyzed here.

The main emphasis is put on national and regional economic specialization and creation of new networks of clusters in the situation of the development of the European Union. We have found that clusterization oriented towards the increase of efficiency of various national and regional economies is a critical precondition for successful creation of modern economy based on knowledge, both in the whole space of the European Union and particular countries.

Another idea - a concept of creation of regional and cross-regional clusters and their networks also known as ,economic oazes"- is suggested here. It is explained in the paper that in the economies based on knowledge development of clusters and their networks will soon become one of the core forms of economic and technological advancement.
\end{abstract}

Keywords: knowledge - based society and economy, integration - and synthesis - oriented strategies, networks of clusters and economic „oases“, European Union, high technology

\section{Introduction}

The future of the European Union lies in the creation of the knowledge based society and knowledge based economy.

This means that key issues that require strategic decisions are to be considered as issues of creation of the knowledge based society and knowledge based economy.

The essence of these issues could be revealed in the following:

- what should the knowledge based society and knowledge based economy be in the future in the European Union?

- how should the knowledge based society and economy be created in the European Union?

Striving to find answers to these questions determines the necessity of elaboration and implementation of appropriate strategies for creation of knowledge based society and knowledge based economy. In its turn, in order to ensure elaboration and implementation appropriate concepts and methodologies of preparation and justification of strategic decisions should be used.

This publication analyzes a new approach towards the way how long term strategies designed to create knowledge based economy in the European Union should be prepared.

This approach is a result of scientific research the object of which has been creation of the knowledge based economy in the situation of the enlargement of the European Union.

The objective of the completed research has been the proof of the fact that key priorities for creation of the knowledge based economy is the urge of technological advancement and enhancement of compatibility and productivity using such opportunities as specialization of national and regional economies, creation of clusters and their networks, as well as the development of so called economic "oases" and hyper-clusters in the entire economic space of the European Union.

The main result of the completed research is the concept of strategies oriented towards integration and synthesis, the basis for which is the universal principle 
of ,creation of a new quality": we should utilize this principle in elaborating and implementing the strategies for creation of knowledge based economy in the European Union.

Key tasks of the completed research have been the following:

- demonstrate the fact that knowledge based society and knowledge based economy in the European Union should be created according to the universal principle of ,creation of a new quality,

- prove the necessity to create and apply the strategies oriented towards integration and synthesis,

- $\quad$ reveal the essence of the rational specialization of national and regional economies,

- $\quad$ show the necessity of creation and expansion of regional, cross-regional and international networks of clusters and economic "oases" in the European Union.

These tasks have been of a priority when attempting to create a modern knowledge based society and knowledge based economy in the European Union.

\section{Creation of knowledge based economies in the European Union as a sphere of complex scientific research}

New challenges for the European Union. The development of the European Union is a very complex process of both quantitative and qualitative transformations.

The necessity for the changes within the European Union is determined by a number of problems which analysis and systematization is described in various scientific papers (Melnikas, B., 2002; Melnikas, B., Reichelt, B., 2004).

Main problems typical to the European Union as a system which require essential and radical decisions are the following:

1. Within the territory of the European Union there are very limited sources of energy and rawmaterials. In the environment of the development of the economy needs for these resources have been steadily growing which means that the European Union becomes more and more dependent on the possibilities for the increase of these resources: we suggest that prospects of economic development of the European Union, along with economic and energetic security of the European Union has been influenced by various economic and political factors characterizing export of these resources to the European Union;

2. Within the countries of the European Union very high standards of living are being implemented here including the spheres of social security and social warranties, as well as environmental protection. As a consequence, all economic endeavors within the territory of the European Union require substantial expenditure which subsequently means that the cost price of the products manufactured in the European Union is very high. The increase of the cost price which is disproportionate to the quality of products determines the fact that products manufactured in the European Union become increasingly incompatible;

3. Key indicator for the well-being in the European Union is the ability to manufacture products to the increasing extent and more massively both in their local and global markets, and sell products of high quality and price. This means that in the European Union the need for more markets in order to sell their own products has increasingly growing (besides, it is of crucial importance that there is an adequately high purchase power). Inadequacy of such markets threatens the development of the economies of the European Union.

Necessity to respond to these problems determines main challenges to the European Union and its development:

1. Quantitative increase of the European Union is orientated to the following:

- European Union could win possibly more markets top sell their production,

- European Union could possibly gain better "direct" access to the countries in Eastern Europe, Central Asia and the Near and Central East where huge supply of energy and raw materials is accumulated and where great potential markets for the products manufactured in the European Union;

2. Qualitative development of the European Union is orientated to the goal to create the knowledge based society and knowledge based economy in the territory of the European Union: This could ensure the following:

- ability to create within the European Union the alternative energy sector and other sectors of 
economy, which could allow strongly decrease the dependence of the economies of the European Union on the import of traditional energy and raw materials,

- ability to create and widely distribute brand new products and technologies in the global which could allow the European Union to become a worldly leader in many spheres of economic and social life.

It is worth mentioning that over the last decade greater possibilities to ensure quantitative increase can be observed in the European Union, whereas in the sphere of qualitative development numerous difficulties and unpredicted obstacles can be seen (Melnikas, B., Reichelt, B., 2004). For this reason qualitative development of the European Union should receive priority consideration: we suggest that prospects of the European Union are basically influenced by creation of the knowledge based society and knowledge based economy.

Scientific research dedicated to the creation of knowledge based economy and its main directions and priorities. Knowledge based economy is a new stage of social and economic development indicating that a society of a new type is being formed which is characterized by new quality of life and new possibilities for further modernization.

Creation of knowledge based economy should be considered as a very important object of scientific research.

As we might know, there are numerous publications in the contemporary scientific research practice dedicated to the creation of knowledge based economy. (Cohendet, P., Stojak, L., 2005; Currie, W., 2000; David, P.A., Foray, D., 2002; Ein-Dor, P., Myers, M., Raman, K.S., 2004; Farnsworth, K., 2005; Goeransson, B., Soederberg, J., 2005; Grace, A., Butler, T., 2005; Hunt, S.D., 2000; Huseman, R.C., Godman, J.P., 1999; Merrill, R.E., Sedgwick, H.D., 1997; Leydesdorff, L., 2004; Steinmueller, W.E., 2002).

Summarizing the completed research allows us to conclude that in addition to the already developed research directions some new and greatly prospective directions might additionally be elaborated: one could expect that the research in the directions mentioned above could allow to define new approaches towards the concept of the knowledge based economies, and the assessment of the conditions necessary for successful implementation of such economy. It is especially important for the new approaches to thoroughly prepare and implement the strategies designed to create knowledge based economy.

Scientific research dedicated to the creation of knowledge based economy can be completed in two important new directions including:

1. To create knowledge based economy it is necessary to evaluate the political, social, cultural, economic, information and technological environment. When completing the research in chosen directions there should be assessed whether political, social, economic, information and technological environment is adequately or inadequately favorable for creation of knowledge based economy: if the findings show that such environment is inadequately favorable, adequate ways to influence this environment should be sought in the course of the research. Main priorities for the research in this direction are connected to definition of common to the entire world phenomena of the economic, social, technological or other progress, along with assessment of features of the development typical to either large regions of the world and various groups of countries (for instance, analyzing possibilities for creation of knowledge based economy it is necessary to thoroughly examine regularities of the development of the European Union and prospects for the quantitative transformations in the economic, social and cultural space of the European Union)

2. Creation of visions and patterns of knowledge based economy. Completing the research in this direction it should be defined what kind of knowledge based economy should be in the future and how it should function. Key priorities of this direction could be:

- structure of the future knowledge based economy,

- principles and mechanisms of the functioning of this economy

- factors of growth, along with orientations of economic, social and political development;

3. Elaboration, justification and implementation of the necessary strategies for the creation and further modernization of the knowledge based economy. Completing research in this direction there should be a decision made about how there will be the transition from current economy to the visionary economy based on knowledge executed; what should the strategies of the transition be; and what should the policies of the 
society and the state be dedicated to the creation to the knowledge based economy. Main priorities of the research in this direction are:

- completion of political, economic, legal and other prerequisites for creation and further development of the knowledge based economy,

- transformation of the current economic system, in order to create future knowledge based economy based on the current one,

- international co-operation in the spheres of innovations and technologies,

- training of human resources in preparation of solid intellectual foundation for the knowledge based economy.

The new directions of the scientific research mentioned earlier reflect on a wide panorama of the issues that should be examined before creating the knowledge based economy. It is obvious that analysis of these issues is directly oriented towards the fact that adequate methods of management are used that would allow to prepare and implement strategies appropriate to the changes happening in the society.

Is the European Union an integral space or an integrated system of various spaces? Processes of the enlargement of the European Union arising currently are very intense.

These processes reflect on two-fold approach towards the European Union and its enlargement:

1. European Union could be perceived as a multicultural space. We suggest that the common cultural space of the European Union is comprised by various ethnic, religious, social and other cultural spaces represented by their regional, as well as quantitative and qualitative indicators. It is of crucial importance that the development of common cultural space in the European Union imply both processes of integration and synthesis: this means that integral culture common to the entire society of the European Union inevitably develops in the European Union;

2. European Union could be perceived as the organization of the states belonging to Europe. This means that it is possible assume that the European Union is generally an organization of organizations because a modern state broadly speaking can be defined as a societal organization of the superior degree of the development. The enlargement of the European Union as an organization of states is going in the way of integration of the new states into this organization, therefore, we suggest that the enlargement of the European Union are followed by the processes of integration. At the same time it is important to notice that the European Union as an organization has gradually started executing functions of the common state of the countries that belong to the European Union and this means that the European Union is gradually turning into the super-state. The development of the European Union as a new super-state simultaneously expresses processes of synthesis typical to the enlargement of the European Union as an organization.

We may conclude that both processes of integration and synthesis develop in the enlargement of the European Union as a multicultural space and as organization of the states. Therefore, the character and condition of the enlargement of the European Union in the future will be determined by what processes of the enlargement will dominate, and whether processes of integration or processes of synthesis will dominate.

Depending on the fact whether in the future the processes of integration or processes of synthesis dominate, it is possible to draft two alternative visions of the future of the European Union:

1. The processes of integration will dominate in the enlargement of the European Union. In this case, multicultural space of the European Union will manifest as a common space comprised by various national cultures and where various nations live. In this case the European Union will continue functioning as the organization of various national states;

2. The processes of synthesis will dominate in the enlargement of the European Union. In this case a new type of common European nation will gradually develop in the space of the European Union, whereas the European Union itself will transform into the integral European super-state. In this case modern national states will become administrative and territorial sub-divisions possessing rather wide autonomy in the future European Union as a super-state. Besides, we may assume that in the future members of the European Union will rather identify themselves with the integral European nation, rather than with current nations of its own.

It is natural that both of these alternative visions are hypothetical. At the same time it is worth noting that the second vision (the vision of the domination of the processes of synthesis) generally is just a continuation of the first vision (the vision of the domination of the 
processes of integration). This means that both of these visions as a complex can be considered as a common hypothesis dedicated to the future of the European Union: in this common hypothesis two stages could be emphasized: the first one (the stage of integration processes) and the second one (the stage of the synthesis process).

It is necessary to mention that regardless the combination of the processes of integration will characterize the enlargement of the European Union; whatever the case is, the development of the knowledge based society and knowledge based economy will manifest in the European Union. The knowledge based society in the future will represent to the entire space of the European Union.

We suggest that the development of the integral cultural space in the European Union is actually a very important precondition to create the knowledge based economy. Consequently, it is very important to thoroughly discuss issues of the development of the integral cultural space in the European Union and entire Europe.

The concept of the integral cultural space in Europe. A characteristic feature of the contemporary époque is intense processes of globalization, embracing all spheres of political, social and economic development and manifesting in all regions of the world. In the process of globalization a society of a new type is being formed, with its typical new values and new striving, which creates new patterns for lifestyle and is confronted to new problems and searches for solutions to these problems.

Globalization processes are very well showing themselves in the modern Europe. It is quite possible to state that the key-feature of globalization in Europe is the fact that an integral European society is being born, which creates and builds on an integral cultural space, as well as integral spaces for social, economic, political, technological, ecological and information development.

This development of the integral cultural space in Europe not only makes preconditions for basic change in life environment and conditions of all European nations, but also determines the fact that a brand new quality is being shaped, both of the society itself and of each European citizen.

The development and further growth of the integral cultural space in Europe is being influenced by a great number of diverse factors. Among these factors as very important appear those related to the expansion of the European Union and to transformation processes in Eastern and Central Europe, meaning that integration of Eastern and Central European countries to the European Union not only indicates the quantitative growth of the European Union (increase in the number of member states, the number of their population, overall territories and economic potential) but also qualitative transformation in the entire Europe. By the way, this particular consideration that integration of the Eastern and Central European countries is directly influencing quantitative changes in the entire Europe demonstrates the significance of the factors mentioned above to the formation of the integral cultural space in Europe.

The development of the integral cultural space in Europe, taking into account the situation of the integration of Eastern and Central European countries to the European Union, is very complex and conflicting process. On one hand, this process opens numbers of new opportunities and perspectives for societal advancement in all Europe, including the countries of Eastern and Central Europe. On the other hand, this process is inevitably causing new problems and new conflicts, and their solutions require that an adequate policy should be created, including the sphere of culture. This means that identification of the new challenges for cultural policies and understanding of the essence of these challenges, as well as capability to properly treat them, makes them tasks of a high priority in the situation of the growth of the European Union.

The importance of the tasks mentioned earlier suggests that theoretical and practical studies designed to better conceive and solve them can be considered as relevant both in scientific and practical sense.

The development of the integral cultural space is a striking sign of the contemporary society in Europe, which allows making a complex definition of political, social, economic and technological process development. The integral cultural space in Europe can be perceived as a portmanteau concept. The easiest way is to see the integral cultural space in Europe as a general system of priority values, stereotypes of social behaviour, lifestyle patterns and moral and spiritual standards, typical to all layers of the European countries.

Such definition of the integral cultural space demonstrates a very important factor: the integrity of the cultural space can be understood as affinity of priority values, stereotypes of social behaviour, lifestyle patterns and moral and spiritual standards to all societal layers in all European countries. Thus, it 
is possible to state that the level of the affinity can determine the integrity of the whole cultural space. The more likeness can be seen within the systems of values, behaviour, lifestyle patterns and standards of different countries and societal layers, the more integral can be their common cultural space be understood. And the opposite: if the systems of values, behaviour, lifestyle patterns and standards of different countries and societal layers do not suggest the idea of common features or suggest the picture of great differences, one may say that the society of these countries does not share the integral cultural space.

When giving comments on the concept of the integral cultural space, it is necessary to accentuate several conditions. First, this definition suggests that one might acknowledge the existence of different systems values, stereotypes of social behaviour, lifestyle patterns and moral and spiritual standards, typical to different countries and societal layers. Similarity or affinity of different systems can be comprehended as an assumption for association of different cultural spaces into integral cultural spaces. Next, this definition demonstrates the idea that the integral cultural space conveys the situation where all keyelements of cultural spaces of different countries and societal layers: this means that the main precondition for the integral cultural space formation is a high level of its internal integrity. Ten, this definition implies that the integral cultural space creates a situation where specific features of particular countries or societal layers may gradually lose their influence on the further growth of these cultures: the critical role of each country's and societal layer's development falls on the processes that start inferring as general processes of the integral cultural space.

Understanding of the problems mentioned above allows us to apply the aforementioned concepts of the integral cultural space in the cases when various problems of European integration and expansion of the European Union arise.

Transformations in the "enlarged" European Union and typicalities characteristic to the development of the integral space in the entire European Union. Main typicalities have developed over the recent decades in the integral economic and social space of the entire European Union. Among those the following could be identified:

- general typicalities characteristic to the development of all large economic and social spaces that make known not only in the situation of the development of the European Union, but also appear in the evolution of all civilisations and cultures,
- specific typicalities characteristic to the development of the European Union in particular, manifesting as historically unique phenomena of the development of civilisations and cultures.

There is no strict boundary between general and specific typicalities characteristic to the development of the integral economic and social space in the European Union.

As general typicalities those can considered that, drawing an analogy in one way or another, have already evolved in the history of the development of other civilizations and cultures. As specific typicalities we can conceive those of the exceptional origin of the European Union, its economic and social space and transformations of this space. It is important to note that among the specific typicalities as most substantial should be respected those that allow to reveal the specificity influenced by various regional factors, including the countries of the Eastern and Central Europe.

There can be enumerated a great number of general typicalities characteristic to the integral economic and social space of the entire European Union. Among those these can be considered as the leading ones:

1. Typicality of the priorities of the quantitative growth and qualitative advancement manifests the fact that the development of the economic and social space in the entire European Union is characterised by the two main priorities: quantitative growth (territory; population numbers; accumulated capital; trade and consumer growth) and qualitative advancement (formation of new life styles and new multicultural spaces; creation and implementation of modern technologies and organizational patterns in all spheres of life; dissemination of new values and living standards; and rise of new opportunities of further growth). This typicality demonstrates that in the situation of the development of the integral economic and social space of the European Union there forms an integral European civilisation of a new type, completely harmonized with the overall system of the Western civilisation, and actively participating in multifaceted co-operation with all modern civilisations and cultures;

2. Typicality of the priorities of democratic attitudes, humanism, human rights and common human values proves that striving to implement the ideals of democracy and humanism is the 
most intrinsic value towards which the development of the European Union is oriented;

3. Typicality of the increasing complexity of the structure of multicultural spaces indicates that in the situation of the development and enlargement of the European Union not only the diversity of the cultures, that appear in the space of the European Union, increases but also processes of the increasing complexity of those cultural systems and structures occur: new characteristics and dimensions of multicultural spaces develop, that testify the increase of the variety of ethnic, confessional, regional, demographic, social, economic, political, ideological, mental and other factors. This trend allows us to state that in the situation of the development and enlargement of the European Union not only the variety of cultural and multicultural spaces inevitably augments, but also qualitatively new problems influenced by this variety arise;

4. Typicality of the balance in general and local factors demonstrates that in the situation of the development and enlargement of the European Union an integral European civilisation of a new type is forming that possess twofold characteristics: first, general characteristics, typical to all spheres of life within the whole space of the European Union; and second, local characteristics, expressing typicalities of different countries, regions and societal layers. Combinations of general and local characteristics make possible to define adaptability of any local space in the common space of the European Union, at the same time indicating the level of the inner harmony within the multicultural spaces;

5. Typicality of predominant norms and standards implies that in the situation of the development and enlargement of the European Union the uniform norms and standards have been steadily prevailing in the integral economic, social and cultural spaces. This typicality embraces all spheres of societal life - the sphere of economics, business and public administration, social behaviour, political and societal life, as well as people's everyday life and even their private lives. The uniform norms and standards comprise both formal and informal rules for behaviour and acts in various life situations, development and dissemination of values and technologies of interpersonal communication. Origination and increasing dominance of uniform norms and standards is a key precondition for gradual development of the integral and undivided European civilisation and culture, where general characteristics have already been prevailing, if compared to national, regional or local characteristics of other kind;

6. Typicality of non-synchronical development suggests that in the situation of the development and enlargement of the European Union more and more uneven changes emerge. As it is known, societal development and headway, and processes occurring in the society may evolve in the way of various discrepancies. These discrepancies can be very diverse, including discrepancies between the pace of the development: they vary from country to country, region to region; they appear to differ in different sectors of economic and social life and different societal layers. Discrepancies in changes can cause conflicts and issues of different kind;

7. Typicality of cyclical development based on the "wave" principle refers to the fact that all processes of the development of the European Union are undergoing cycles: each cycle includes a certain stage of development, that can be outlined by both quantitative and qualitative changes. This means that the transition of these stages can be compared to certain "waves": where each wave witnesses the stepping stone of the potential of the European Union, as an integral economic and social space;

8. Typicality of increasing differentiation and differentiation variety exhibits that in the situation of the expansion of the European Union, within the integral economic and social space new manifestations of differentiation occur, and the range of differentiation expands. It is especially notable for the reason that in the actual routine of the development and expansion of the European Union rather substantial contradiction appears: on one hand, following political declarations, it is sought to align regional structures, which by the level of their development are rather unequal; economic sectors or societal layers; on the other hand, a real "alignment" is of limited scale and applies only to particular spheres of social and economic life. It is quite probable that actual differentiation is generally increasing: various discrepancies between different regions, economic sectors and 
societal layers deepen, within actual opportunities for improvement and modernisation, as well as actual well being and social security. This factor is essential, estimating prospectives for stability and internal security in the space of the European Union;

9. Typicality of balance of centripetal and centrifugal forces in the situation of the development and expansion of the European Union is seen in the simultaneous manifestation of two opposite tendencies: on one hand, it is a tendency of striving to enter the common system, expressing the priority of obedience to the system; and on the other hand, a tendency of striving to strengthen the sovereignty and autonomy in the common system, expressing the priority of the self-assurance of personal wellbeing at the expense of the system. Those two tendencies are advantageous for the wellbeing of the European Union, provided they are mutually well balanced; such balance in its turn, can have different manifestations, including rational combination of basics of centralisation, decentralisation and self-government in the systems of managing and administering processes of expansion and development. (It is noteworthy mentioning that in cases, when the balance among centripetal and centrifugal forces fails, more threats for the performance of the entire system emerge: disproportionate prevalence of the centripetal forces may lead to inefficient management and determine loss of adaptability skills in the ever-changing environment, whereas disproportionate prevalence of centrifugal forces impels fragmentation and self-destruction of the system itself. This means that vulnerability of the balance mentioned above is a very dangerous and undesirable matter.);

10. Typicality of predominance of traditional leaders proposes that in the situation of the development and expansion of the European Union the priority interests to be implemented are those developing in greater countries of the Western Europe, such as, first Germany and France (these countries have historically formed as traditional leaders of the European Union). Despite the fact that in the situation of the development and enlargement of the European Union one can observe a great variety of concerns of different countries, regions and layers of the society (moreover, this variety causes internal disagreements within the
European Union), prevalence of traditional leaders and their concerns is long-lasting and steady. By the way, the concerns of the traditional leaders play as a key factor for the development of norms and standards, typical to the space of all the European Union;

11. Typicality of the expansion potential expresses the idea that the European Union as an integral system has been increasingly operating within global economic, social, cultural, informational and political spaces. With this regard, the increasing expansion of the European Union, as an integral system, towards the spheres of the world economies and the process of the entire political, social and economic development;

12. Typicality of the adaptability in the consistently changing external and internal environment suggests that in the situation of the development and enlargement of the European Union multifaceted processes of adaptation arise: the new member states of the European Union need to adapt in the new to them space of the European Union, whereas the "old" members of the European Union have to adapt to the "enlarged" European Union and "accept" new members as equal partners; besides, all European Union as an integral system needs to adapt to the consistently changing external environment. All this allows us to admit that adaptability is a crucial precondition for the further development of the European Union as an integral system.

The typicalities described above, characteristic to the development and enlargement of the European Union as an integral system, within the group of typicalities of this kind could be considered as of the most importance. At the same time, among very important and critical several specific typicalities exist.

Specific typicalities characteristic to the development and enlargement of the European Union as an integral system,are multifaceted. Some of these typicalities reflect on the specificity of a particular époque, whereas the others express specificity of particular regions, spheres of social and economic development or certain layers of the society.

Among specific typicalities expressing current era these are the most notable:

1. Typicality of regulated and controlled liberalisation that reveals rather contradictory processes typical to the current development of 
the European Union. A key feature of these processes is the following: on one hand, traditions of liberal democracy have been increasingly implemented in the society and there are apparent signs of economic liberalisation; on the other hand, both in economic and social life the "masked autocracy" has been observed which is executed by various forms of increased bureaucracy, growing regulation and limitation of the activities in different spheres, along with the increasing austere rule.

In modern world in many spheres of life one can observe a substantial decline of norms and ideals of liberalism, despite the "formal" promotion or declaration of liberalism. We may admit that in the modern European Union the new kind of society has been increasingly developing, with both liberalism and social awareness, where, however, liberalism will be regulated and controlled with the increasing power: every subject of any activity in all spheres of life will have opportunities of liberal choice and selfdetermination with increasing boundaries and decreasing "degree" of freedom. (It is a paradox that in the modern European Union, in the situation of promotion of liberal values, bureaucratic and clerical arguments of the societal development have been strongly increasing, and new trends of centralised management emerge, that manifest in many spheres of political, social and economic life);

2. Typicality of promotion and predominance of the concerns of large economic subjects demonstrates that both in overall situation of globalisation and in the specific economic and social space of the European Union processes of concentration of economic activities have steadily happening. The actual situation in both economic space of the European Union and global markets has been increasingly influenced by activities and opportunities of large economic subjects (here we consider large economic subjects those large enterprises that operated in international markets, networks and organisations of small and medium enterprises, and various international corporations and international economic organisations). In the situation of the development and enlargement of the European Union more and more obvious becomes promotion and predominance of the concerns of large economic subjects: on one hand, this situation reinforces competitive abilities of economic subjects representing economic spaces of the European Union; on the other hand, opportunities to develop free competition and initiative are violated (the violations of this kind have been increasingly growing, although public policy in economies of the European Union proclaims provisions for free competition and initiative support).

3. Typicality of the declining role of the state as a structure for the organization of the society indicates that in the situation of the development and enlargement of the European Union in national countries the state as a key organisational structure for any society of any country has increasingly losing its previous importance and a number of opportunities to immediately influence situation in the country. In the environment of the development and enlargement of the European Union the situation in its member states has been steadily influenced by overall processes of development and enlargement of the European Union as a system on one hand; and potential, development and growth of the non-governmental, non- state and private sectors. The declining role of states has been determined by such processes as development of common economic and social space in the European Union, where the principles of liberal labour force mobility, capital mobility and product and services mobility are implemented; moreover, the increasing enhancement of globalisation, and international economic, cultural and informational relations has been also influencing the overall decline of the significance of particular states;

4. Typicality of manifestation of threats and issues of a new kind allows us to conceive that each stage of the development and enlargement of the European Union reveals new threats and cause new issues that are determined by various factors of moral, ideological, cultural, political, social, economic, ecological, military and informational character. Ability to immediately understand these threats and issues, as well as develop and implement effective means for prevention in the modern situation in principle expresses the typicality of the development and enlargement of the European Union.

The analysis of the typicalities described above is very important for creation of knowledge based society and knowledge based economy in the European Union. 


\section{Strategies designed to create knowledge based economy in the European Union}

Networks of clusters, economic „oases“ and rational specialization of regional economies as a priority prerequisite, ensuring possibilities for creation of knowledge based economy in the European Union. Contemporary economic principles and practices confirm that in efficiently operating economic systems their surplus value is created at greater extent. This statement works in all cases where ways to increase efficiency and compatibility on the scale of both particular economic subjects and large national and regional economic systems (Boldrin, M., Canova, F., 2001; Bond, E., Syropoulos, C., Winters, L.A., 2001; Chortares, G.E., Pelagidis, T., 2001; Dutta, M., 1999; Guy, M., 2001; Redding, S.,Venables, A.J., 2004; Sangmon, K., 2002)

The main precondition to ensure high efficiency and compatibility of any economic system is to achieve that any economic system should be properly specialised. Hummels, D., Ishii, J., Kei - Mu Yi, 2001; Huseman, R. C., Godman, J. P., 1999; Melnikas, B., 1997; Olsen, T. E., Osmundsen, P., 2003).

Under the proper specialisation we understand the situation where the range of products produced within the economic system guarantees magnification of the surplus value within this system: the economic system should be exceptionally orientedtowards the series of products, services and activities, whose structure allows to achieve potentially greater surplus value or higher velocity of the increase of this value.

For the sake of the rationalisation of the national or regional economic system various means may be implemented. These means should create a solid complex, and have to be long-term and consecutive. The idea of the means should ensure that the entire economic system of particular region or country is developed as a large macro-cluster or hyper-cluster. These large macro-or-hyper-clusters may be multiprofiled and oriented towards creation of different and diverse final products, and it is very important to create final products that are compatible in global markets.

It is obvious that large macro-or-hyper-clusters in particular countries or regions should meet the following requirements:

- large clusters of this kind function as open systems, maintaining both internal and external economic and technological relations in international and global markets,

- inside of the large clusters of this kind various specialised clusters can be created within incorporated diverse institutions of science, research and education, enterprises of production and services, business incubators, parks of science and technology, centers for innovation, and industrial, trade, transportation and communication companies.

Development of large economic systems in a way of clusterisation may be of great variety. A very prospective method to implement this way is creation of regional (territorial) or sectorial "oases".

In general "oasis" can be explained as an economic system, possessing extremely advantageous political, legal, economic and other conditions for activities and development. These conditions are as a rule exclusive and in their presence the "oasis" as economic system receives various privileges or extremely beneficial environment is created for it. "Oases" can be established on behalf of political will of a state or even a group of states: by the way, the idea of regional "oases" is very viable in the improvement and implementation of regional policy of the European Union, with the intentions of creation of "oases" not only in particular countries, but also regions, comprised of regions of different countries.

Regional "oasis" is one where exceptionally advantageous conditions for economic development are created in a territorially outlined area (region). This area may coincide with systems of administrative territorial division of particular countries or may not.

Sectorial "oasis" is one where exceptionally advantageous conditions are created for particular branch of economy, and particular segments of business or public sector.

Creating and developing "oases" it is very important to consider demographic situation, possibilities to attract, concentrate and efficiently utilise human and financial and other resources, as well as possibilities rapidly expand various innovations.

The idea of the "oases" and opportunities to promote this idea in the situation of the development of the European Union has been described quite comprehensively (Melnikas, B., 2002, 2003, 2004).

Summarizing the statements given above, we may confirm that the concepts of proper rationalization of national and regional economic systems, as well as concepts of creation of macro-or-hyper-clusters and "oases" are of great importance, ensuring progress in the entire space of the European Union.

The idea of clusters, their networks and "oases", 
oriented towards rationalism of specialization of regional economies is very promising, when creating the knowledge based economy in the European Union. The implementation of this concept should be based on the universal principle of ,,creation of a new quality" when planning to prepare and implement appropriate strategies oriented towards integration and synthesis.

Priority strategies oriented towards integration and synthesis designed to create knowledge based economies in the European Union. In order to create knowledge based society and knowledge based economy in the European Union we should purposefully and consecutively implement the strategies oriented towards integration and synthesis embracing all major spheres of social, economic and cultural life.

Considering the fact that when creating the knowledge based economy the key priority should be put on clusterization, networks of clusters, economic "oases" and rational specialization of regional economies we suggest that: for the benefit of creation of knowledge based economy in the European Union it is necessary to prepare and implement a complex of strategies for clusterization and rational specialization of regional economies.

The strategies for clusterization and rational specialization of regional economies should include both the strategies oriented towards integration and the strategies oriented towards synthesis: the strategies oriented towards integration and the strategies oriented towards synthesis are characterized by different purpose and different content.

The idea of the strategies oriented towards integration is to ensure high efficiency and compatibility of different regional economies and different sectors of both in the integral economic space of the European Union and in global markets. These strategies should draw upon the following key decisions:

- each national or regional economic system should shape up one or more priorities oriented towards creation of modern state-of-the-art technologies and products based on them: based on such priorities one could define or develop rational specialization of each national or regional economy,

- each national or regional economic system according to the regional priorities, should form regional economic ,oases “ and clusters; whereas general „oases“ and clusters can be transformed into macro-or hyper-clusters on the scale of large regions or the entire country (the clusters of this kind can be of a broad scope, multi-scope and limited scope, functioning as specialized clusters in particular sectors of economy),

- creation of „oases“ and clusterization should ensure that the major role in the grow of economy is to be played by intellectual resources and technological advancement. The idea of the strategies oriented towards synthesis is to achieve that major sectors of economy on the scale of the whole European Union operate as integral undivided systems.

Each sector of this kind as a system should possess a very high level of technological development and should be a leader in the corresponding sphere of economy on the worldly scale. Orientation towards the challenges of this kind requires that within these strategies the following decisions are made:

- on the scale of the entire European Union the networks of regional and sector clusters as well as "oases" should be created and mutually developed: each element in the networks of this kind could become rationally specialized which would allow to make sure that the network as a system is of a state-of-the-art level of productivity and technological advancement,

- the networks of regional and sector clusters as well as "oases" should be specialized: subsequently, the networks of this kind on the scale of economic space of the European Union are mutually complementing and function based on partnership,

- the networks of regional and sector clusters as well as "oases" that are created in the European Union can operate outside the European Union: this will ensure the viability of economic structures of the European Union and their compatibility in the global markets,

- the networks of regional and sector clusters as well as "oases in the future should be an organizational basis for the economies of the entire European Union: the networks of this kind should be understood as the key structural elements of the economy of the European Union, as well as a key organizational structure of the knowledge based economy (it is obvious that in any of these networks high intellectual, information technical and other potential should be accumulated ensuring rapid and efficient headway of technologies and leadership in the global markets).

Implementation of the strategies explained above is a very important factor to achieve that creation of 
knowledge based economy and knowledge based society in the European Union become a reality.

To conclude the statements given earlier it is also worth noting that purposeful and consecutive development and implementation of the strategies oriented towards integration and synthesis ensures that integral and undivided and highly efficient knowledge based society and knowledge based economy gradually form within the European Union.

\section{Conclusions and recommendations}

Creation of the knowledge based society and knowledge based in the European Union is a very complex, long-term and ambiguous process.

Key challenges and priorities that require main attention when creating the knowledge based society and knowledge based economy are the following:

1. Creation of knowledge based society and knowledge based economy in the European Union should be oriented towards the solution of the following problems:

- problems of insufficiency and increase in the cost of energy and raw-material, as well as problems of secure and reliable import of these resources, along with problems of creation of alternative energy and economies oriented towards alternative raw materials,

- problems of new prospective markets necessary for implementation of production in the European Union, and problems of its development and introduction,

- problems of the required potential development for state-of-the-art products, as well as problems of compatibility of the products oriented towards high technologies in the global markets,

- problems of social security, economic wellbeing, as well as social, legal and ecological environment improvement;

2. The basis for creation of the knowledge based economy in the European Union is the implementation of the universal principle of ,creation of a new quality" designed to complete the following:

- development of the society and economy of a new type is going under concurrent processes of integration and synthesis,

- when creating the knowledge based society and knowledge based economy in the European Union integral cultural space should be created,
- when creating the knowledge based society and knowledge based economy in the European Union the strategies oriented towards integration and synthesis should be created and implemented;

3. In the strategies designed to create the knowledge based economy in the European Union main emphasis should be put on the following priorities:

- rational specialization of national and regional economies, ensuring high compatibility both in the European Union and in global markets,

- transformation of national, regional and sector economies into the macro-or hyper-clusters and systems of such clusters,

- development of clusters and networks of economic "oases" in the entire space of the European Union,

- further development of clusters and networks of economic "oases" as key organizational structures characteristic to the system of the European Union;

4. In the situation of the further development of the European Union the following provisions should be implemented:

- issues of modernization and compatibility increase for the national, regional and sector systems should be tackled in the strategies oriented towards integration,

- issues related to creation of the integral and undivided knowledge based society and knowledge based economy should be tackled in the systems oriented towards synthesis in the entire space of the European Union.

Further scientific research and practice dedicated to creation of strategies for the knowledge based society and knowledge based economy in the European Union are greatly promising and important.

\section{References}

Altvater, E.; Mahnkopf, B. (1996), Limits of Globalisation: Politics, Economy and Ecology in the World Society Muenster, Verlag Westfalisches Dampfboot, 33 p.

Armstrong, M. A. (1999), Handbook of Human Resource Management Practice - London, Kogan Page, 922 p.

Boldrin, M.; Canova, F. (2001), "Inequality and convergence in Europe?s regions: reconsidering European regional policies", Economic Policy, vol.16, issue 32, p. 205. 
Bond, E.; Syropoulos, C.; Winters, L. A. (2001), "Deepening of regional integration and multilaterial trade agreements", Journal of International Economics, vol.53, issue 2, p. 335-361.

Calori, R.; Atamer, T., Nunes, P. (1999) The Dynamics of International Competition - London, Sage Publications, $256 \mathrm{p}$.

Chortareas, G. E., Pelagidis, T. (2004), "Trade flows: a facet of regionalism or globalisation ?" Cambridge journal of economics, vol.28, p. 253-271.

Cultures in Central and Eastern Europe / Ed. M. Bateman. (1997), Oxford, Boston, Butterworth - Heinemann, $238 \mathrm{p}$.

Cohendet, P.; Stojak, L. (2005), "The digital divide in Europe. The economic and social issues related to "knowledge-based Europe", Futuribles: Analyse et Prospective, issue 305, p. 5-28.

Currie, W. (2000), The Global Information Society Chichester, John Wiley, 288 p.

David, P. A.; Foray, D. (2002), "An introduction to the economy of the knowledge society", International Social Science Journal, issue 171, p. 5-9.

Dicken, P. (1998), Global Shift: Transforming the World Economy - London, Sage Publications; A. Paul Chapman Publishing, 512 p.

Dutta, M. (1999), Economic Regionalisation in the AsiaPacific: Chalenges to Economic Cooperation. Cheltenham, Edward Elgar Publishing, 318 p.

Ein-Dor, P.; Myers, M.; Raman, K. S. (2004) "IT industry and the knowledge economy: A four country study", Journal of Global Information Management, vol. 12, issue 4, p. 23-49.

Farnsworth, K. (2005), "Promoting business-centred welfare: International and European business perspectives on social policy", Journal of European Social Policy, vol. 15, issue 1, p. 65-80.

Garrett, G.; Mitchell, D. (2001), "Globalization, Government, Spending and Taxation in OECD Countries", European Journal of Political Research, vol.39, N3

Gerber, J. (1999), International Economics-Amsterdam, Addison Wesley Longman, $512 \mathrm{p}$.

Ghose, A. K. (2004), "Global ineguality and international trade", Cambridge journal of economics, vol.28, issue 2, p. $229-252$

Goeransson, B.; Soederberg, J. (2005), "Long waves and information technologies - On the transition towards the information society", Technovation, vol. 25, issue 3, p. 203-211.

Grace, A.; Butler, T. (2005), "Beyond knowledge management: Introducing learning management systems", Journal of Cases on Information Technology, vol. 7, issue 1, p. 53-70.

Guy, M. (2001), "Regionalisation in Africa: Integration and
Disintegration, Africa Today, vol.48, N2, pp.154 - 157.

Hayo, B.; Seifert, W. (2003), "Subjective economic wellbeing in Eastern Europe", Journal of Economic Psychology, vol.24, issue 3, p. 329-348

Hofbauer, H. (2003), Osterweiterung. Vom Drang nach Osten zur peripheren EU - Integration - Wien, Promedia, $240 \mathrm{~S}$.

Hummels, D.; Ishii, J.; Kei-Mu Yi.(2001) "The Nature and Growth of Vertical Specialization in World Trade", Journal of International Economics, vol.54, p.75-96

Hunt, S. D. (2000), A General Theory of Competition: Resources, Competences, Productivity. Economic Growth - London, Sage Publications, 256 p.

Huseman, R. C.; Godman J. P. (1999), Leading with Knowledge: The Nature of Competition in 21 st. Century - London, Sage Publications, 272p.

Yarbrough, B. V.; Yarbrough, R. M. (1999), The World Economy; Trade and Finance - Chicago, The Dryden Press, $758 \mathrm{p}$.

Krugman, P.; Obstfeld, M. (1997), International Economics - Amsterdam, Addison Wesley Longman, 800 p.

Lavingne, M. (1995), The Economics of Transition : From Socialist Economy to Market Economy - London, Macmillan Press, 295 p.

Leydesdorff, L. (2004), “The university - industry knowledge relationship: Analyzing patents and the science base of technologies", Journal of the American Society for Information Science and Technology, vol. 55, issue 11, p. 991-1001.

McNally, R. (1999), The Comprehensive World Atlas Stamford, Longmeadow Press, 224 p.

Melnikas, B. (1997), “The Integrations Problems of the Baltic States: Possibilities for the Formation of a Unified Technological, Economic and Social Space" East West Scientific Cooperation. Science and Technology Policy of the Baltic States and International Cooperation. NATO ASI Series, 4, Science and Technology Policy. - Dordrecht; Boston: Kluwer Academic Publisher, Vol.15. p. $33-51$.

Melnikas, B.(1999), Probleme der Integrattion der baltischen Staaten in westliche Strukturen (Berichte des Bundesinstituts fuer ostwissenschaftliche und internationale Studien), N 40, Koeln, 1999, 42 S.

Melnikas, B.; Jakubavičius, A.; Strazdas, R. (2000), Inovacijos: verslas, vadyba, konsultavimas - Vilnius, Lietuvos inovaciju centras, $240 \mathrm{p}$.

Melnikas, B.(2002), Transformacijos. - Vilnius, Vaga, 750p.

Melnikas, B., Reichelt, B. (2004).Wirtschaft und Mentalitaet: Tendenzen der EU-Osterweiterung Leipzig, Leifim - Verlag, 159 S.

Merrill, R. E.; Sedgwick, H. D.(1997), The New Venture Handbook - New York, Amacom, 256 p.

Olsen, T. E.; Osmundsen, P. (2003), "Spillovers and International Competition for Investments", Journal of 
International Economics, vol.59, issue 1, p. 211-238

Parker, B. (1998), Globalisation and Business Practice: Managing Across Boundaries-London, Sage Publications, $672 \mathrm{p}$.

Perraton, J. (2001), "The global economy - myths and realities", Cambridge journal of economics, vol.25, pp. 669-684

Politische und oekonomische Transformation in Osteuropa / Hrsg. G.Brunner, (2000), Baden Baden, Nomos, 252 $\mathrm{S}$.

Porter, M. (1980), Competitive Strategy: Techniques for Analyzing Industries and Competitors - New York, The Free Press, 396 p.

Redding, S.; Venables, A. J. (2004), "Economic geography and international ineguality", Journal of Inernational Economics, vol.62, issue 1, p.53-82.

Rosenzweig, P. (2001), Accelerrating International Growth - Chichester, John Wiley, 275 p.
Salvatore, D. (1990), International Economics - New York, Macmillan Publishing Company, 670 p.

Sangmon, K. (2002), “A Longitudinal Analysis of Globalization and Regionalization in International Trade: Social Network Approach", Social Forces, vol. 81, N2, p.445-471.

Steinmueller, W. E. (2002), "Knowledge - based economies and information and communication technologies", International Social Science Journal, issue 171, p. 141154.

The Sustainability of Long - Term Growth: Socioeconomic and Ecological Perspectives / Ed. M. Munasinghe, O.Sunkel, C de Miguel, (2001) - Cheltenham, Edward Elgar Publishing, 464 p.

Tandon, Yash. (1999), The World Trade Organisation and Africas Marginalisation", Australian Journal of International Affairs, vol.53, N1, p.83-94. 